\title{
Papers
}

\section{Role of radiography in predicting progression of osteoarthritis of the hip: prospective cohort study}

\author{
Max Reijman, J M W Hazes, H A P Pols, R M D Bernsen, B W Koes, S M A Bierma-Zeinstra
}

\begin{abstract}
Objectives To investigate which variables identify people at high risk of progression of osteoarthritis of the hip.

Design Population based cohort study.

Setting Ommoord district in Rotterdam, Netherlands. Participants 1904 men and women aged 55 years and older from the Rotterdam study were selected on the basis of the presence of osteoarthritic signs on radiography at baseline, as defined by a Kellgren and Lawrence score $\geq$ grade 1 .

Main outcome measures Radiological progression of osteoarthritis of the hip, defined as a decrease of joint space width $(\geq 1.0 \mathrm{~mm})$ at follow-up or the presence of a total hip replacement.

Methods Potential determinants of progression of hip osteoarthritis were collected at baseline. $x$ Ray films of the hip at baseline and follow-up (mean follow-up time 6.6 years) were evaluated. Multivariate logistic regression models were used to assess the association between potential risk factors and progression of hip osteoarthritis.

Results In 13.1\% (1904 subjects) of the study population (mean age 66.2 years), progression of hip osteoarthritis was evident on the radiograph. Starting with a simple model of only directly obtainable variables, the Kellgren and Lawrence score at baseline, when added to the model, was a strong predictor (odds ratio 5.8, 95\% confidence interval 4.0 to 8.4 ), increasing to 24.3 (11.3 to 52.1) in subjects with hip pain at baseline.

Conclusions The Kellgren and Lawrence score at baseline was by far the strongest predictor for progression of hip osteoarthritis, especially in patients with existing hip pain at baseline. In patients with hip pain, a radiograph has strong additional value in identifying those at high risk of progression of hip osteoarthritis.
\end{abstract}

\section{Introduction}

Osteoarthritis of the hip is one of the main causes of disability among elderly people, and its prevalence will increase with the ageing of the Western society. ${ }^{12}$ Identifying people at high risk of rapid progression of osteoarthritis is important for at least two reasons. Firstly, well characterised "high risk" groups may be useful in clinical trials, and, secondly, assuming that disease modifying drugs for osteoarthritis become available in the future, primary target groups in need of such treatment should be identified. Additionally, identified people whose osteoarthritis has not progressed can be given some reassurance about their disease status.

No consensus has been reached on how to define progression of hip osteoarthritis. ${ }^{3}$ International committees have suggested evaluating structural (joint space narrowing) as well as symptomatic variables of osteoarthritis (pain, functional impairment, overall assessment by the patient) in clinical studies. ${ }^{45} \mathrm{~A}$ potential composite outcome measure is the need for surgery (total hip replacement), based on the assumption that total hip replacement operations are performed only in patients who have severe symptomatic osteoarthritis together with structural damage of the hip. ${ }^{67}$

Potential factors that may identify people at risk of progression of hip osteoarthritis include systemic factors (metabolic, hormonal, genetic, and related to age or sex), local biomechanical factors (such as mechanical workload), body mass index and acetabular dysplasia, and already existing osteoarthritic changes such as signs visible on radiograph, clinical symptoms, and signs of cartilage degradation. In a recent review, Lievense et al reported that radiological features were the main mediators of progression of hip osteoarthritis ${ }^{8}$; however, all the included studies had a small study population, follow-up was short, and the studies were hospital based.

We investigated in a large open population with a long term follow-up period which easily measurable factors (clinically relevant risk factors) will best identify patients at high risk of progression of osteoarthritis of the hip.

\section{Methods}

The study population consisted of participants of the Rotterdam study, a prospective cohort of men and women aged 55 years and older. The objective of the Rotterdam study is to investigate the incidence of, and risk factors for, chronic disabling diseases; the rationale and study design have been described previously. ${ }^{9}$ Each participant gave written informed consent.

All 10275 inhabitants of the district of Ommoord in Rotterdam, Netherlands, received an invitation to participate. The response rate was $78 \% ; 7983$ subjects participated in the study. Of these participants, 6450 visited a research centre for a baseline examination. Of these, 3585 revisited the centre after six years' follow-up, and 1920 had signs of osteoarthritis that were visible on a radiograph at baseline, as defined by a Kellgren and Lawrence score of 1 or greater. We excluded subjects with a hip fracture $(n=16)$ during the follow-up period; the resulting study population comprised 1904 participants. We conducted baseline measurements between 1990 and 1993 and follow-up measurements between 1996 and 1999, with a mean follow-up time of 6.6 years.

The Kellgren and Lawrence score is on bmj.com 
Our study group had to be mobile enough to visit the research centre at baseline and at follow-up and survive the follow-up period, which implies a healthy cohort effect. Our study group was younger than the total population of Rotterdam and had a lower prevalence of disability of the lower limb and of hip pain, as reported earlier. ${ }^{10}$

\section{Radiographical assessment}

Weight bearing anteroposterior radiographs (with the subject in a standing position) of the hip and knee were obtained at $70 \mathrm{kV}$ (focus 1.8, focus to film distance $120 \mathrm{~cm}$, Fuji High Resolution G $35 \times 43 \mathrm{~cm}$ film). Radiographs of the pelvis were obtained with both feet in $10^{\circ}$ internal rotation and the $\mathrm{x}$ ray beam centred on the umbilicus, and of the knee with the patellae in central position. For the hand, we obtained standard anteroposterior radiographs. One trained reader (MR) evaluated the radiographs of the hip obtained at baseline and at follow-up, unaware of the clinical status of the patients. Three trained readers independently evaluated the baseline radiographs of the knee and the hand, also unaware of the clinical status of the patients. All radiographs of the hip were grouped by patient and read by pairs in chronological order, which was known to the reader (chronologically ordered reading procedure). ${ }^{11}$

\section{Outcome measure}

We defined progression of osteoarthritis of the hip as a joint space narrowing of $1.0 \mathrm{~mm}$ or more or a total hip replacement at follow-up. At baseline and follow-up we used a $0.5 \mathrm{~mm}$ graduated magnifying glass laid directly over the radiograph to measure the minimal joint space width of the hip joints. ${ }^{12}$ We measured the lateral, superior, and axial compartments of the hip, as described previously by Croft et al. ${ }^{12}$ We defined joint space narrowing as the joint space width of baseline minus of follow-up.

\section{Potential predictors of progression}

\section{Radiographical predictors}

At baseline, we used measurements of the Kellgren and Lawrence score, which is based on an atlas of examples of radiographs, to quantify osteoarthritis of the hip, knee, and hand on radiograph (in five grades; see bmj.com) ${ }^{13}{ }^{14}$ We considered a patient to have osteoarthritis on radiograph of the hip or knee, if his or her score was 2 or higher. We defined osteoarthritis of the hand on radiograph as a score of 2 or higher in at least one of two joints out of the three groups of hand joints (distal interphalangeal, proximal interphalangeal, and first carpometacarpal).

The interrater reliability of the hip was 0.68 for the Kellgren and Lawrence score ( $\kappa$ statistics) and 0.85 (intraclass correlation coefficient) for the minimal joint space width, as reported earlier. ${ }^{15}$ Two independent observers scored the radiographs of the knee for signs of osteoarthritis, as described previously. ${ }^{16}{ }^{17}$ For the hand, an interrater reliability was reported for the Kellgren and Lawrence score of 0.68 and 0.77 ( $\kappa$ statistics). ${ }^{18}$

\section{Predictors collected by questionnaire}

At baseline, trained interviewers conducted an extensive home interview, dealing with demographic characteristics, medical history, risk factors for chronic diseases, and use of medication. We used a modified version of the Stanford health assessment questionnaire to assess disability of the lower limb and obtained a lower limb disability index by calculating the mean score of the answers to six questions, as described previously (range 0-3). ${ }^{15} 17$ We asked for the presence of hip pain ("Did you have joint pain of your right or left hip during the last month?") and morning stiffness ("Did you experience morning stiffness of the hips?"). We collected data on age at and type of menopause (spontaneous or artificial); menopause was defined as the cessation of menses for at least one year. For women reporting spontaneous menopause, we defined age at menopause as the self reported age at which the last menstruation occurred..$^{19}$ We asked for the family history of osteoarthritis in parents and siblings and for current or last occupation including the duration in years of this occupation. A job title scheme used at Statistics Netherlands was the basis for coding the jobs. ${ }^{20}$ We considered a subject to be exposed to heavy mechanical workload if the subject performed heavy physically demanding work and the exposure time of this job was longer than eight years.

\section{Predictors collected by physical examination}

At the research centre, we performed a clinical examination. We measured height and weight, with participants wearing indoor clothing without shoes. We calculated body mass index as weight in kilograms divided by height in metres squared $\left(\mathrm{kg} / \mathrm{m}^{2}\right)$; our definition of obesity was a body mass index of $30 \mathrm{~kg} / \mathrm{m}^{2}$ or more. We measured blood pressure at the right brachial artery, using a random zero sphygmomanometer with the participant in sitting position; we used the mean of two consecutive measurements in our analysis. We defined hypertension as a systolic blood pressure of $160 \mathrm{~mm} \mathrm{Hg}$ or higher or a diastolic blood pressure of $95 \mathrm{~mm} \mathrm{Hg}$ or higher, or current use of antihypertensive drugs for the indication of hypertension. ${ }^{21}$ We considered diabetes mellitus present when the subject reported using antidiabetic drugs (code A010 of the World Health Organization's anatomical therapeutical chemical classification system of 1992), or when the serum glucose concentration before and after load was equal to or higher than $11.0 \mathrm{mmol} / \mathrm{l}^{2.2}$

In a subset of 525 subjects, we tested the range of motion. With the participants in a supine position, we tested internal and external rotation, flexion, and extension of the hips.

\section{Statistical analysis}

Of all potential predictors of progression we first performed univariate logistic regression analyses and used factors with $\mathrm{P}<0.1$ for the multivariate analyses. For these we chose a practical approach, and in two different models we assessed which predictors best identified people with progression of hip osteoarthritis.

Model 1-In the first model we included only those factors that are easily and directly obtainable by the doctor, such as age, sex, family history of osteoarthritis, age at menopause, hypertension, diabetes, body mass index, mechanical workload, disability of the lower limb, presence of hip pain, and morning stiffness.

Model 2-In the second model we added the information obtained from additional radiographical testing; we used the Wald test (with a cut-off value of $\mathrm{P}=0.05$ ) to assess whether radiographical factors offered additional value to model 1 .

Additionally we used classification tables of observed cases compared with predicted cases to assess the proportion correctly predicted by each model.

To investigate which factors will identify the progressors of hip osteoarthritis in a clinical situation we repeated the same procedure for those subjects with existing hip pain at baseline. We considered pain as a potential marker for symptomatic osteoarthritis of the hip.

Of the 1904 participants, we used only the hips with a Kellgren and Lawrence score of 1 or higher for analyses (2918 hips). We calculated odds ratios, by means of generalised estimating equations, to estimate the associations between the 
Table 1 Baseline characteristics of the study population and univariate associations with progression of hip osteoarthritis. Values are numbers (percentages) of participants unless otherwise indicated

\begin{tabular}{|c|c|c|}
\hline & Study population ( $n=1904)$ & Odds ratio $(95 \% \mathrm{Cl})$ \\
\hline Women & $1005(52.8)$ & $2.0(1.6 \text { to } 2.6)^{*}$ \\
\hline Mean age in years (SD) & $66.2(7.0)$ & $1.1(1.1 \text { to } 1.1)^{*}$ \\
\hline Body mass index $\geq 30 \mathrm{~kg} / \mathrm{m}^{2}$ & $240(12.6)$ & $1.6(1.1 \text { to } 2.2)^{*}$ \\
\hline Type 2 diabetes & $166(8.7)$ & 0.9 (0.6 to 1.3$)$ \\
\hline Hypertension & $585(30.7)$ & $0.9(0.7$ to 1.1$)$ \\
\hline Family history of osteoarthritis & $244(12.8)$ & $1.4(1.0 \text { to } 2.0)^{*}$ \\
\hline \multicolumn{3}{|l|}{$\begin{array}{l}\text { Age at menopause (reference } \\
\text { group }>50 \text { ): }\end{array}$} \\
\hline$\leq 45$ & $\begin{array}{l}463 \text { (24.3) Should these not } \\
\text { add up to } 1005(52.8 \%)\end{array}$ & $1.3(0.9 \text { to } 1.9)^{*}$ \\
\hline $46-50$ & $703(36.9)$ & $1.6(1.1 \text { to } 2.2)^{*}$ \\
\hline Heavy mechanical workload & $242(12.7)$ & $0.8(0.5$ to 1.1$)$ \\
\hline Presence of hip pain & $187(9.8)$ & $3.4(2.5 \text { to } 4.6)^{*}$ \\
\hline Lower limb disability & $255(13.4)$ & $3.2(2.5 \text { to } 4.3)^{*}$ \\
\hline Presence of morning stiffness & $571(30.0)$ & $1.7(1.3 \text { to } 2.2)^{*}$ \\
\hline $\begin{array}{l}\text { Joint space width at baseline } \\
\leq 2.5 \mathrm{~mm}\end{array}$ & $145(7.6)$ & $7.2(5.2 \text { to } 9.9)^{*}$ \\
\hline \multicolumn{3}{|l|}{ Osteoarthritis on radiograph } \\
\hline Hip $\geq$ grade 2 & $191(10.0)$ & $8.9(6.8 \text { to } 11.6)^{*}$ \\
\hline Grade 2 & $156(8.2)$ & \\
\hline Grade 3 & $27(1.4)$ & \\
\hline Grade 4 & $8(0.4)$ & \\
\hline Knee & $345(18.1)$ & 1.0 (0.6 to 1.4$)$ \\
\hline Hand & 451 (23.7) & $2.0(1.5 \text { to } 2.6)^{*}$ \\
\hline
\end{tabular}

Progression of the hip was defined as a joint space narrowing $\geq 1.0 \mathrm{~mm}$ or a total hip replacement at follow-up.

${ }^{*} \mathrm{P}<0.1$

potential predictors and progression of the hip. We used this procedure because this method takes into account the correlation between the left and right hip, with each patient as the observation unit and the hips as repeated measurements. ${ }^{23}$ We entered those variables that had a univariable relation with progression (two sided $\mathrm{P}<0.1$ ) in the multivariable model. We performed multivariable, stepwise (backward and forward) logistic regression and entered variables with $\mathrm{P}<0.05$ into the model. Of the selected variables we assessed the final estimates by the enter method (all selected variables were entered into the model at once).

We adjusted all multivariate analyses for follow-up time. We used SPSS, version 11.0 (SPSS, Chicago, USA) and SAS software, version 8.2 (SAS Institute, Cary, NC) for all analyses.

\section{Results}

Table 1 presents baseline characteristics of the study population, and the univariate associations with progression of hip osteoarthritis. In this study population with a mean age of 66.2 years, $13.1 \%$ had progression of osteoarthritis of the hip on radiograph after a mean follow-up time of 6.6 years. Of these patients, $35.8 \%$ had an incident total hip replacement during the follow-up period.

Table 2 shows the associations between predictors and progression of osteoarthritis of the hip on radiograph in the total study population for the two models used. The first model showed that age (per year), sex (female), a lower limb disability index of 0.5 or greater, and the presence of hip pain were independent predictors of progression of osteoarthritis of the hip as seen on radiograph. When we added radiographical factors to this model we found that especially a Kellgren and Lawrence score of 2 or higher at baseline had a strong independent additional $(\mathrm{P}<0.0001)$ association with progression of osteoarthritis of the hip as seen on radiograph (odds ratio 5.8).
Table 2 Association between predictors and progression of osteoarthritis of the hip of complete study population in two models ( $n=2918$ hips). Values are odds ratios (adjusted for follow-up time) with $95 \%$ confidence intervals

\begin{tabular}{|c|c|c|}
\hline Predictor variable & $\begin{array}{l}\text { Model } 1 \text { (clinical } \\
\text { variables) }\end{array}$ & $\begin{array}{l}\text { Model } 2 \text { (including } \\
\text { radiological variables) }\end{array}$ \\
\hline Age in years & 1.07 (1.05 to 1.09$)$ & 1.06 (1.04 to 1.08$)$ \\
\hline Sex & 1.7 (1.3 to 2.2$)$ & 1.8 (1.4 to 2.4$)$ \\
\hline Disability index score $\geq 0.5$ & 1.9 (1.4 to 2.6$)$ & - \\
\hline Presence of hip pain & 2.6 (1.9 to 3.7$)$ & 2.4 (1.7 to 3.5$)$ \\
\hline $\begin{array}{l}\text { Baseline joint width space } \\
(\leq 2.5 \mathrm{~mm})\end{array}$ & - $^{*}$ & 1.9 (1.2 to 2.9$)$ \\
\hline $\begin{array}{r}\text { Baseline Kellgren and } \\
\text { Lawrence grade } \geq 2\end{array}$ & - $^{*}$ & 5.8 (4.0 to 8.4$)$ \\
\hline Correctly predicted by model & 0.875 & 0.897 \\
\hline
\end{tabular}

Predictors were included in a model with $\mathrm{P}<0.05$.

Progression of osteoarthritis of the hip was defined as a joint space narrowing $\geq 1.0 \mathrm{~mm}$ or a total hip replacement at follow-up.

${ }^{*}$ Not tested in this model.

We repeated the same procedure for those subjects with prevalent hip pain at baseline $(\mathrm{n}=411)$. We found a much stronger association of a baseline Kellgren and Lawrence score of 2 or higher with progression of osteoarthritis of the hip as seen on radiograph with an odds ratio of 24.3 (additional to model $1, \mathrm{P}<0.0001$, table 3). Surprisingly, age lost its relevance in the second model. The probability of a Kellgren and Lawrence score of 2 or higher after the test was $74.6 \%$ (probability before test $27.4 \%$ ).

In addition we repeated all analyses in a subset $(n=525)$ for whom data on limited range of motion were available. In this subset we found that a restricted flexion of the hip of more than $20 \%$ had an independent association in the final model (odds ratio $3.1,95 \%$ confidence interval 2.1 to 4.7 ) with progression of osteoarthritis of the hip as seen on radiograph. However, the strong additional value of radiographical findings still holds.

The figure shows the proportion of subjects with a joint space narrowing of $1 \mathrm{~mm}$ or more or an incident total hip replacement, of the open population and of those with probably symptomatic hip osteoarthritis, stratified by Kellgren and Lawrence score at baseline. All subjects with a Kellgren and Lawrence score of 4 at baseline had had total hip replacement operations at follow-up. Of the subjects with hip pain and a Kellgren and Lawrence grade of 2 at baseline, 73\% developed progression during follow-up, compared with $36 \%$ in the total study population.

\section{Discussion}

In this large, population based, prospective cohort study with long term follow-up we found that a Kellgren and Lawrence

Table 3 Association between predictors and progression of osteoarthritis of the hip for 411 participants with hip pain in two models. Values are odds ratios (adjusted for follow-up time and duration of hip pain longer than a year) with $95 \%$ confidence intervals

\begin{tabular}{lcc} 
& Model 1 (clinical variables) & $\begin{array}{c}\text { Model } 2 \text { (including } \\
\text { radiological variables) }\end{array}$ \\
\hline Age in years & $1.07(1.02$ to 1.12$)$ & - \\
\hline Disability index score $\geq 0.5$ & $3.1(1.7$ to 5.9$)$ & - \\
\hline $\begin{array}{l}\text { Baseline Kellgren and } \\
\text { Lawrence score } \geq 2\end{array}$ & * $^{\star}$ & 24.3 (11.3 to 52.1) \\
\hline Correctly predicted by model & 0.752 & 0.854 \\
\hline
\end{tabular}

Predictors were included in a model with $\mathrm{P}<0.05$.

Progression of osteoarthritis of the hip was defined as a joint space narrowing $\geq 1.0 \mathrm{~mm}$ and the presence of hip pain at follow-up or a total hip replacement at follow-up. ${ }^{*}$ Not tested in this model. 


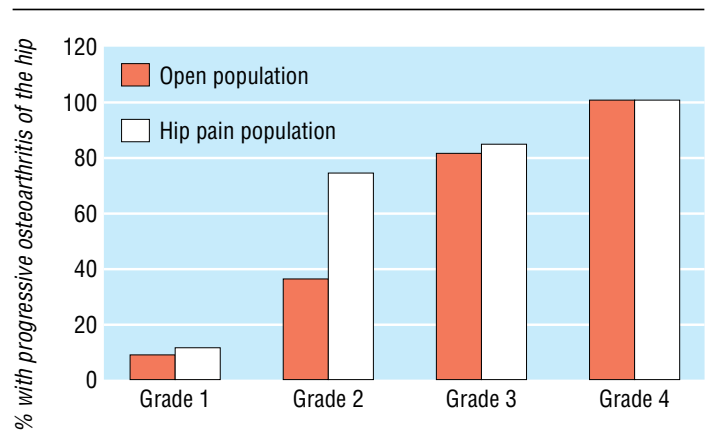

Proportion of subjects with a joint space narrowing of $1 \mathrm{~mm}$ or more or a total hip replacement by Kellgren and Lawrence grade at baseline

score of 2 or higher at baseline was the strongest identifier of people at high risk of progression of hip osteoarthritis. This holds particularly true for patients with hip pain at baseline. In addition, a lower limb disability index of 0.5 or higher was also an independent identifier of these high risk patients.

\section{Predictors for progression of osteoarthritis of the hip}

In the total study population, the independent predictors for progression of osteoarthritis of the hip were age, female sex, the presence of hip pain, joint space width at baseline $\leq 2.5 \mathrm{~mm}$, and a Kellgren and Lawrence score of 2 or higher at baseline. These findings are in agreement with those reported by Lievense et al. ${ }^{8}$ In subjects who consulted a general practitioner for hip pain, Birrell et al showed that a simple scoring system based on the severity of symptoms as seen on radiograph and clinical measures could clearly identify groups at high likelihood of being put on a waiting list for a total hip replacement procedure. ${ }^{24}$ The results of our study and the two studies mentioned earlier support the conclusion that progression of hip osteoarthritis is most strongly associated with signs of the presence or severity of osteoarthritis-in other words, with the disease status of the subject. The absence of an association between body mass index and progression of hip osteoarthritis in our study was also reported by Lievense et al. ${ }^{8}$

\section{Were important predictors missed?}

Strikingly, all other potential predictors of progression that are independent of the disease were excluded when signs of the presence or severity of hip osteoarthritis were added to the model. We expected that especially local biomechanical factors (such as mechanical workload and sports activity) would have independent associations with the progression of osteoarthritis of the hip. A possible explanation for the lack of association in our study may be that we used information about historical workload and not of workload during the follow-up period. We may therefore have missed information about important predictors of progression of hip osteoarthritis in our study, such as mechanical load during follow-up of an already existing osteoarthritic joint.

\section{Limitations of the study}

A possible limitation of our study is the presence of health based selection bias; overall, participants were generally healthier than non-participants. Therefore, the generalisability of the reported findings is likely to hold, particularly for those subjects who are mobile enough to visit a doctor. Another limitation is that the model was tested only in the chosen population. Because we used an open study population, albeit subdivided for people with hip pain, our model should be validated in a clinical setting and predictive values assessed subsequently.

\section{What is already known on this topic}

Osteoarthritis of the hip is one of the main causes of disability among elderly people, and the prevalence of hip osteoarthritis will increase

The main mediators of progression of hip osteoarthritis are, based on small hospital based studies with a short follow-up time, radiological features

\section{What this study adds}

In a clinical situation and for clinical trials, an x ray film has strong additional value to identify people who are at high risk of progression of hip osteoarthritis

\section{Conclusions}

A Kellgren and Lawrence score of 2 or higher at baseline is the strongest predictor of progression of hip osteoarthritis, especially in people with hip pain at baseline. In a clinical situation and for clinical trials, an x ray film has strong additional value in identifying people at high risk of progression of hip osteoarthritis.

We thank E Odding, H A Valkenburg (who died in April 2005), and A P Bergink for scoring the radiographs of the knee, S Dahaghin and U Cimen for scoring the radiographs of the hand, and F van Rooij, E van der Heijden, $\mathrm{R}$ Vermeeren, and L Verwey for collection of follow-up data. Moreover, we thank the participating general practitioners, the pharmacists, the many field workers at the research centre in Ommoord, and all participants.

Contributors: MR, JMWH, and SMABZ had the idea for the study. MR and SMABZB managed the study. MR, HAPP, JMWH, RMDB, and SMABZ were responsible for the analysis and interpretation of the data. All authors commented on the paper. SMABZ is the guarantor.

Funding: This study was supported by a grant from the Dutch Arthritis Association.

Competing interests: None declared.

Ethical approval: Medical Ethics Committee of the Erasmus Medical Center.

1 Felson DT, Zhang Y. An update on the epidemiology of knee and hip osteoarthritis with a view to prevention. Arthritis Rheum 1998;41:1343-55

2 Felson DT, Lawrence RC, Dieppe PA, Hirsch R, Helmick CG, Jordan JM, et al. Osteoarthritis: New insights. part 1: the disease and its risk factors. Ann Intern Med 2000;133:635-46.

3 Dougados M, Guegen A, Nguyen M, Berdah L, Lequesne M, Mazieres B, et al. Radiological progression of hip osteoarthritis: definition, risk factors and correlations with clinical status. Ann Rheum Dis 1996;55:356-62.

4 Altman RD, Brandt KD, Hochberg MC, Moskowitz RM. Design and conduct of clinical trials in patients with osteoarthritis: recommendations from a task force of the trials in patients with osteoarthritis: recommendations from a task
Osteoarthritis Research Society. Osteoarthritis Cartilage 1996;4:217-43.

5 GREES. Recommendations for the registration of drugs used in the treatment of osteoarthritis. Ann Rheum Dis 1996;55:552-7.

6 Dougados M, Guegen A, Nguyen M, Berdah L, Lequesne M, Mazieres B, et al. Requirement for Total hip arthroplasty: an outcome measure of hip osteoarthritis? J Rheumatol 1999;26:855-61.

7 Dougados M. Monitoring osteoarthritis progression and therapy. Osteoarthritis Cartilage 2004;12(suppl.A):S55-60.

8 Lievense AM, Bierma-Zeinstra SMA, Verhagen AP, Verhaar JAN, Koes BW. Prognostic factors of progress of osteoarthritis of the hip: a systematic review. Arthritis Rheum 2002:47:556-62.

9 Hofman A, Grobbee DE, Jong PT de, VandenOuweland FA. Determinants of disease and disability in the elderly: the Rotterdam Elderly Study. Eur I Epidemiol 1991;7:403-

10 Reijman M, Hazes JMW, Bierma-Zeinstra SMA, Koes BW, Christgau S, Christiansen C, et al. A new marker for osteoarthritis: cross-sectional and longitudinal approach. Arthritis Rheum 2004;50:2471-8

11 Auleley G, Girardeau B, Dougados M, Ravaud P. Radiographic assessment of hip osteoarthritis progression: impact of reading procedures for longitudinal studies. Ann Rheum Dis 2000;59:422-7.

12 Croft P, Cooper C, Wickham C, Coggon D. Defining osteoarthritis of the hip for epidemiologic studies. Am J Epidemiol 1990;132:514-22.

13 Kellgren JH, Lawrence JS. Radiological assessment of osteo-arthrosis. Ann Rheum Dis 1957;16:494-502.

14 Kellgren JH, Jeffrey MR, Ball J. The epidemiology of chronic rheumatism. Atlas of standard radiographs of arthritis. Oxford: Blackwell, 1963

15 Reijman M, Hazes JMW, Pols HAP, Bernsen RMD, Koes BW, Bierma-Zeinstra SMA Validity and reliability of three definitions of hip osteoarthritis: cross-sectional and longitudinal approach. Ann Rheum Dis 2004;63:1427-33. 
16 Bergink AP, Meurs JB, Loughlin J, Arp PP, Fang Y, Hofman A, et al. Estrogen receptors alpha gene haplotype is associated with radiographic osteoarthritis of the knee in elderly men and women. Arthritis Rheum 2003;48:1913-22.

17 Odding E, Valkenburg HA, Algra D, Vandenouweland FA, Grobbee DE, Hofman A Associations of radiological osteoarthritis of the hip and knee with locomotor disability in the Rotterdam study. Ann Rheum Dis 1998;57:203-8.

18 Dahaghin S, Bierma-Zeinstra SMA, Reijman M, Pols HAP, Hazes JMW, Koes BW. Prevalence and determinants of one-month hand pain and hand-related disability in the elderly. The Rotterdam study. Ann Rheum Dis 2005;64:99-104.

19 Weel AE, Uitterlinden AG, Westendorp IC, Burger H, Schuit SC, Hofman A, et al Estrogen receptor polymorphism predicts the onset of natural and surgical menopause. J Clin Endocrinol Metab 1999;84:3146-50.

20 Standaard Beroepenclassificatie. Voorburg/Heerlen: Centraal Bureau voor de statistiek. 1985.

21 World Health Organization, International Society of Hypertension Guidelines for the Management of Hypertension. Guidelines subcommittee. J Hypertens 1999;17:151-83.

22 World Health Organization. Technical report series 727. Vol Diabetes Mellitus. Geneva: WHO, 1985.
23 Zhang Y, Glynn RJ, Felson DT. Musculoskeletal disease research: should we analyze the joint or the person? J Rheumatol 1996;23:1130-4

24 Birrell F, Afzal C, Nahit E, Lunt M, Macfarlane GJ, Cooper C, et al. Predictors of hip joint replacement in new attenders in primary care with hip pain. $\mathrm{Br} J$ Gen Pract 2003;53:26-30.

(Accepted 24 March 2005)

doi $10.1136 / \mathrm{bmj} .38442 .457488 .8 \mathrm{~F}$

Erasmus Medical Center, PO Box 2040, 3000 CA Rotterdam, Netherlands Max Reijman clinical epidemiologist

J M W Hazes professor of rheumatology

H.A.P Pols professor of internal medicine

R M D Bernsen statistician

B W Koes professor of general practice

S M A Bierma-Zeinstra biomedical scientist

Address for correspondence: M Reijman m.reijman@erasmusmc.n 